DEMOGRAPHIC RESEARCH

VOLUME 33, ARTICLE 46, PAGES 1271-1280

PUBLISHED 15 DECEMBER 2015

http://www.demographic-research.org/Volumes/Vol33/46/

DOI: $\quad$ 10.4054/DemRes.2015.33.46

Descriptive Finding

\title{
How integrated are immigrants?
}

\section{Pierluigi Contucci}

\section{Rickard Sandell}

(C) 2015 Pierluigi Contucci \& Rickard Sandell.

This open-access work is published under the terms of the Creative Commons Attribution NonCommercial License 2.0 Germany, which permits use, reproduction \& distribution in any medium for non-commercial purposes, provided the original author(s) and source are given credit. See http://creativecommons.org/licenses/by-nc/2.0/de/ 


\section{Table of Contents}

$1 \quad$ Introduction $\quad 1272$

2 Quantifying integration and defining full integration $\quad 1272$

3 Empirical illustration: The case of Spain $\quad 1274$

4 Discussion $\quad 1276$

5 Conclusion 1277

6 Acknowledgements 1277

$\begin{array}{ll}\text { References } & 1279\end{array}$ 


\title{
How integrated are immigrants?
}

\author{
Pierluigi Contucci ${ }^{1}$
}

Rickard Sandell ${ }^{2}$

\begin{abstract}

\section{BACKGROUND}

The successful integration of immigrants is seen as a principal means to secure economic growth and welfare in many countries. Success in this task depends on the capacity to formulate effective integration policies, which in turn is based on research capable of describing and explaining the integration process properly.
\end{abstract}

\section{OBJECTIVE}

Our objective is to define a conceptual and quantifiable measure of full immigrant integration. This enables a quantitative evaluation of how integrated immigrants are in a specific context in an immigrant - native system - a question poorly addressed by past research.

\section{METHODS}

Our approach consists of looking at the functional dependency of different integration quantifiers on immigrant density. The empirical analysis uses register data from Spain. We focus on social integration and labour market integration in formal employment.

\section{RESULTS}

In our empirical analysis we find dramatic differences in immigrant integration levels across integration contexts. While labour market integration approaches the level of full integration, social integration quickly declines as immigration levels surge. It is shown that these differences are primarily due to the presence of social network effects in the social integration process, absent in the labour market integration process.

\section{CONCLUSIONS}

Proper identification of integration deficits and its causes is likely to improve the efficiency of integration policy making, and the capacity to reach integration targets. Our framework has this quality. The research presented here shows that full labour market integration of immigrants is a realistic target. However, it also shows that, if left unattended, the segregation forces contained in social networks, quite dramatically obstruct the social

\footnotetext{
${ }^{1}$ Dipartimento Di Matematica, Universitá di Bologna. E-Mail: Email.

${ }^{2}$ Departamento de Ciencias Sociales, Universidad Carlos III de Madrid. E-Mail: sandellrick@gmail.com.
} 
Contucci \& Sandell: How integrated are immigrants?

integration process. Lack of social integration undermines the strategy of reliance on increasing immigration to secure future economic well-being that many governments and international organizations are in the process of adopting.

\section{Introduction}

Immigrant integration is a political priority. Both OECD and the European Union have declared that its achievement plays a key role in future growth, social cohesion and wellbeing (European Commission 2010; OECD 2014). At the same time, we witness frequent mass-media coverage of integration-related problems and a global surge in outspoken anti-immigration political parties. This mismatch between objectives and reality in terms of integration is not unique to our time (Casteles and Miller 2009). Despite the enduring nature of integration problems and their political relevance, simple but paramount questions regarding the integration process remain unanswered. Examples of such questions are: How integrated are a country's immigrants? How does the integration process respond to a rise in immigration? Which mechanisms drive the process?

Here we argue that attending to these questions scientifically bring to the surface important information about how to cope with integration challenges more effectively. To this end, we illustrate a method which, using register data, extracts precise quantitative answers to this type of question. We look at two integration contexts - labour market integration and social integration. The lesson that the data teach us is that the former is an integration process with the intrinsic ability to absorb an increase of immigration, while the latter is not. Data and theoretical analysis also suggest that these differences are due primarily to the social network effects governing social integration, and which are found absent in formal labour market integration. When social network effects are present, the progress of integration is seriously delayed as immigration rises. Hence, policy makers wanting to promote global integration effectively must cope with two opposed processes operating at significantly different speeds.

\section{Quantifying integration and defining full integration}

To answer the simple questions on integration performance and progress, we opt for a systemic approach to integration. A systemic approach is methodologically different from traditional integration studies. The latter are primarily preoccupied with explaining the multiple causes operating on individual integration outcomes, and predominantly engaged with time series analysis. ${ }^{3}$ A systemic approach operates at a different analytical

\footnotetext{
${ }^{3}$ See Van Tubergen (2006) and Alba and Nee (2005) for a summary discussion. In traditional integration studies systematic differences in integration outcomes are typically associated with age, sex, education, language pro-
} 
level. An example of a systemic approach would be to assess the functional dependency of an integration quantifier such as, for example, local intermarriage rates, on a variable describing an important characteristic of the system, such as, for example, local immigrant density. Furthermore, the functional dependency is assessed regardless of space and time coordinates or any individual or contextual characteristics. In what follows we show that, while losing the details of the micro level structure, a systemic approach, using significantly fewer variables than traditional accounts, effectively benchmarks integration processes. We also show that this approach can uncover the underlying nature of different integration processes in a society.

To answer the question of how integrated immigrants are we first have to define integration, and more importantly, when an immigrant population is fully integrated. Take the fraction of inter-marriages in a municipality. An immigrant minority population is completely segregated from the native majority population if the fraction of inter-marriages is zero in the municipality under study. With a systemic approach, it is easy to define a fully integrated immigrant population with respect to a given quantifier. This notion follows from the concept of indistinguishability. When the fraction of immigrants is $\gamma$ (gamma), a simple computation shows that if immigrants and natives are indistinguishable the fraction of inter-marriages in a large population is $2 \gamma(1-\gamma)$.

To understand the meaning of full integration between two groups beyond its mathematical expression, an ideal experiment example can be useful. Let us say that an experimenter works with numerous subjects. The experimenter secretly and randomly assigns to each of the subjects a colour, yellow or red, with proportions $\gamma$ (for yellow) and $(1-\gamma)$ (for red). Thereafter, he invites the subject to couple together if they like. Some of them do, others stay single. Repeating the experiment many times, he will observe that the probability to have a mixed couple is exactly $2 \gamma(1-\gamma)$ because the two coloured groups are indistinguishable.

We refer to observed integration values falling on the line defined by $2 \gamma(1-\gamma)$ as full integration. In addition, we emphasize that the previous formula is important beyond the numerical value of the coefficient 2 , because it states the linear growth of the quantifier with respect to the parameter $\Gamma=\gamma(1-\gamma)$.

ficiency, and other individual characteristics (Cortina, Esteve, and Domingo 2008; Hwang, Saenz, and Aguirre 1997; Qian, Glick, and Batson 2012). Likewise, contextual features such as culture, ethnic-group-size and local heterogeneity levels in terms of ethnicity and race are reported to be influential when assessing immigrant integration outcomes across groups (Qian, Glick, and Batson 2012; Blau, Blum, and Schwartz 1982; Portes and Zhou 1993). 


\section{Empirical illustration: The case of Spain}

Using empirical data and suitably averaging over a nation's municipalities Barra et al. (2014), have shown that one can expand the single municipality example to encompass the whole human ecosystem in a country. Their analysis uses unique Spanish data on social integration, drawn from the period 1999-2008; labour market integration, drawn from the period 2005-2010; and finally, immigration data for the period 1999-2010. During the first decade of the $21^{\text {st }}$ century, Spain received about 5,5 million immigrants, which correspond to $85 \%$ of its total immigrant stock in 2010. Here we replicate the findings in Barra et al. (2014) to render a measure of observed integration. ${ }^{4}$

Next, in Figure (1) we compare the observed immigrant integration - as reported by Barra et al. (2014) - and the measure of full immigrant integration - as defined above. This analysis is conducted for a) labour market integration - expressed as the rate of temporary and indefinite formal labour contracts given to immigrants in Spain ${ }^{5}-$ and b) social integration - expressed as inter-marriages and the rate of newborns with one native and one immigrant parent in Spain. The defined integration quantifiers are modelled as a function of immigrant density $(\gamma)$. Immigrant density is obtained using information on the number of all immigrants - regular and irregular - in a location. ${ }^{6}$

\footnotetext{
${ }^{4}$ See Barra et al. (2014), its methodological and empirical appendix, for a full account of data, model, proofs, and empirical tests.

${ }^{5}$ By formal employment, we refer to all employees that have their labour contract registered with the Spanish Social Security Agency. It should be noted that formal employment is a special case of labour market integration. For example, one could also consider informal labour or both formal and informal labour together. However, and as explained in detail by Barra et al. (2014), fine grained data at the local level is a prerequisite for using our statistical model. Data on informal labour is only available at the province level in Spain. At this level of aggregation our model is no longer viable. Hence, choosing formal employment over any other measure is primarily driven by data availability on native and immigrant employment at the local level. Still, we believe that we would reach similar conclusions regarding immigrants' labour market integration if we had used information on both informal and formal employment instead. Cebolla and González (2008) have shown that immigrants are overrepresented in the informal labour market in Spain. Hence, adding information about participation in informal labour would make immigrants look more integrated than we are lead to believe using only information on formal employment.

${ }^{6}$ All data is public and available free of charge. Data on local immigrant densities is based on the information contained in the Statistics over residential variation in Spanish municipalities, the so-called Estadistica de variaciones residenciales (EVR). This data is unique, since it includes irregular immigrants. EVR is administered by the Instituto Nacional de Estadistica (INE). Data on marriages and births are drawn from the local offices of Vital Records and Statistics across Spain (Registro Civil), and have been compounded and made available by the INE. Data on labour contracts come from Spain's Continuous Sample of Employment Histories (the so called Muestra Continua de Vidas Laborales or MCVL). This data is administered by the Ministry of Labour and Social Security (Ministerio de Empleo y Seguridad Social), and made available on demand by the ministry. For a more exhaustive account of the data and preparation see Barra et al. (2014). Due to the fact that data is only available from 2005 in the case of MCVL, we analyse the functional dependency of labour market integration on immigrant density using data drawn from the period 2005-2010. We analyse the functional dependency of social integration on immigrant density using data drawn from the period 1999-2008. For a more exhaustive account of the data, preparation, and modelling see Barra et al. (2014).
} 
Figure 1: $\quad$ Comparison of observed and full immigrant integration
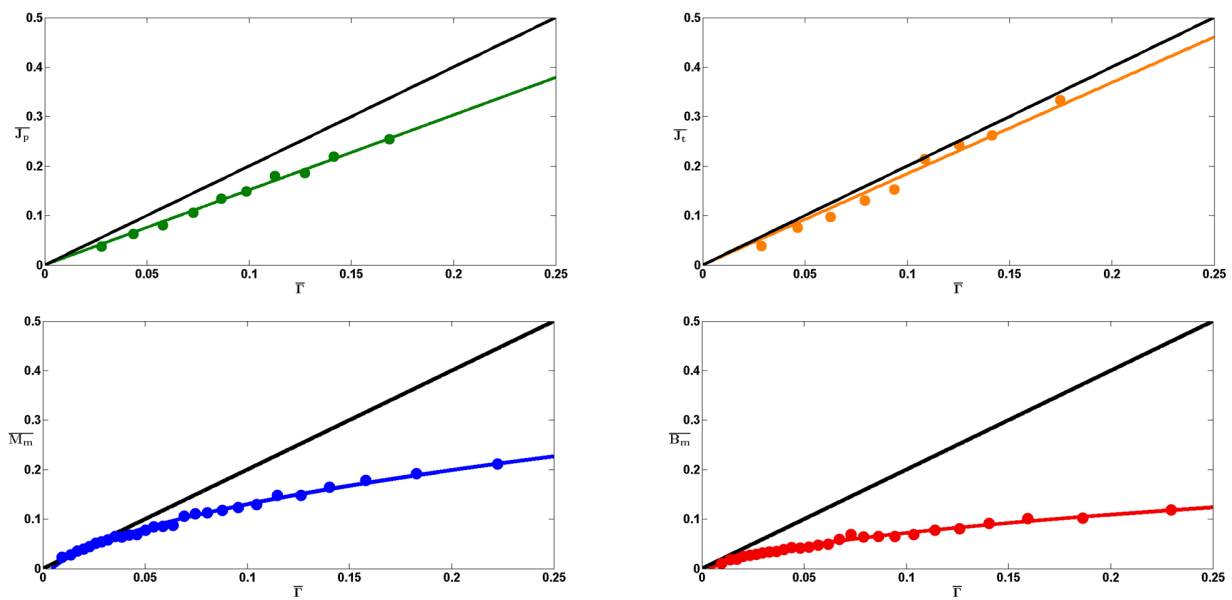

Note: The panels show integration quantifiers versus immigration rates in Spain. Included are: coloured data points, best fit of the same color, and full integration levels in black. Green data - upper left panel - are the percentage of permanent jobs given to immigrants, orange data - upper right panel - are the percentage of temporary jobs given to immigrants. Blue data - lower left panel - are the percentage of mixed marriages and finally red data - lower right panel - are the percentage of newborn children from mixed couples.

The results of this analysis uncover a complicated social reality. We can see that while the formal labour market integration process (upper panel in figure 1) approaches full integration regardless of the size of $\gamma$, its social counterpart (lower panel in figure 1) is dramatically lagging behind. More specifically, starting from an immigration density of $1 \%$ and a formal labour market integration $E$ it will take a density of $2 \%$ to reach $2 E$, a density of $3 \%$ to reach $3 E$ and so on. On the contrary, starting from a social integration $S$ at a density of $1 \%$ it will take a density of $4 \%$ to reach $2 S$, a density of $9 \%$ to reach $3 S$, a density of $16 \%$ to reach $4 S$, and so on. The gap between formal labour market- and social-integration is therefore quickly increasing.

This finding illustrates in a very explicit way some difficulties ahead for societies that, for example, progressively need to rely on labour migration to sustain current levels of welfare and economic growth. The Spanish system experiences close-to-full labour market integration in terms of formal employment, regardless of number of immigrants in the system, whereas social integration quickly decreases and stagnates well below full integration as immigration rises. It shows that having to rely on immigration and the successful integration of immigrants to secure the "economic" future seems unrealistic, if the growing social integration deficit is not addressed when and if immigration levels rise. 
The analysis, moreover, identifies an important source for the observed differences. A detailed theoretical analysis performed with mathematical modelling in Barra et al. (2014), see also (McFadden 2001; Gallo, Barra, and, Contucci 2009), suggests that a linear increase in cross-group couplings over immigrant density of the type we observe for labour market integration, is due to a stochastic independence of individual choices. This implies that employer-employee decisions, whether to engage in a mixed nativeimmigrant labour contract, are made independently from other employer-employee decisions. In other words, social network effects are unimportant in this integration context.

This is not the case for social integration. The observed non-linear (square root) growth of the probability for cross-group couplings against immigrant density is due to the fact that individual choices are interdependent. (Barra et al. 2014; Brock and Durlauf 2001; Contucci, Gallo, and Menconi 2008; Contucci and Giardina 2008; Gallo, Barra, and, Contucci 2009). That is, the action of inter-marrying (or having a child) are decisions that are contingent on how others (natives and immigrants) in the environment have acted in this context before (Weber 1978; Barra et al. 2014; Kalmijn 1998). Consequently, social networks are decisive in social integration processes such as inter-partnership formation in the host society. ${ }^{7}$

\section{Discussion}

The spring-board for high overall integration is the social integration process. Our analysis shows that it is well described by a system of strongly correlated agents. That is, choices affecting inter-partnership decisions are mostly delegated to social networks through an interaction mechanism. This means that to achieve high overall integration in this system, the interaction mechanism that generates the segregating forces has to be identified and neutralized by means of policies. The question is, how? Our systemic approach has the ability to guide us in this work. Our quantitative analysis describes the average behaviour of the integration process across numerous localities in the system under study, and the standard deviations (Agliari et al. 2014; Barra et al. 2014). Therefore, once having established the characteristics and performance of a particular integration process, we can easily extract information about fluctuations around the mean values with a view to identify localities in the system that over and under-perform. Analysing these deviations systematically leads us to potential best and worst practices in the system.

Furthermore, international comparison and benchmarking of integration efforts are lagging because of lack of efficient comparative measures of the integration phenomena

\footnotetext{
${ }^{7}$ One important issue is whether types of integration, particularly labour market integration, have a different functional form in times of an economic crisis such as before and after the recent financial breakdown that started in 2007 and which Spain just begun to recover from. Elsewhere, we have shown that the functional dependency is the same in and out of a crisis (Contucci, Sandell, and Seyedi 2015).
} 
(Lanzieri 2012). Provided that suitable (statistically robust) data are available, regional and international comparisons are easily accomplished using our framework. Such international or interregional comparisons would help in identifying those cases whose performance stands out, and are likely to contain important clues on how to promote social integration processes as immigration levels rise. Future research in this area should also consider important aspects such as, for example, language and cultural characteristics, which, due to the complexity of such an analysis, is beyond the scope of this article. ${ }^{8}$

\section{Conclusion}

We have shown that a systemic approach can be an effective tool for assessing quantitatively the level of integration in a specific context in a society. We also show the model's efficiency in unveiling the nature of the integration process. In this case the results indicate dramatic differences across integration contexts. If left unattended, these discrepancies may undermine the immigration strategy adopted by many governments and international organizations. Consequently, and as a complement to traditional micro level studies of integration phenomena, we point to the necessity to probe for data that can describe and quantify the systemic evolution of the integration phenomenon in the way suggested here. It can also be argued that an analysis of the systemic evolution of integration is a powerful complement to more complex explanatory models targeting individual differences in integration outcomes. Used in the right way, and given that we can detect the presence of social network effects with a minimum of variables, a systemic approach can guide explanations of individual integration outcomes, and in this way improve policy measures aimed at stimulating integration.

\section{Acknowledgements}

We thank Adriano Barra and Cecilia Vernia for interesting conversations throughout this work. We also like to thank two anonymous reviewers and the Associate Editor Stephen Matthews for their suggestions and comments on an earlier version of this work. Pierluigi Contucci acknowledges partial support from FIRB grant RBFR10N90W and from PRIN grant 2010HXAW77. Rickard Sandell acknowledges partial financial suport from the projects "Migration And Care/Domestic Work In Two Institutional Contexts: A Multi-

\footnotetext{
${ }^{8}$ It should be emphasised that subdividing data into more precise groups could provide better and more specific information. However, this sub-division rapidly (with just three to five subgroups) start to endanger the statistical strength of the results and weaken the conclusions. This is a limitation of our method, because it demands statistical robustness of data. Subdividing in groups result in fewer observations per analytical unit and less control over the fluctuations, and consequently less statistical power.
} 
Contucci \& Sandell: How integrated are immigrants?

Tier Design 2012-2016", granted by The Bank of Sweden Tercentenary Foundation (P111111:1), and "Competition Adaptation and Labour-Market Attainment of International Migrants in Europe (CALMA)" granted by the VI National Plan for Scientific Research, Spanish Ministry of Economy and Competitiveness (CSO2012-38521). 


\section{References}

Agliari, E., Barra, A., Contucci, P., Sandell, R., and Vernia, C. (2014). A stochastic approach for quantifying immigrant's interactions. New Journal of Physics 16 (10): 1030-34.

Alba, R. and Nee, V. (2005). Remaking the American mainstream: Assimilation and contemporary immigration. Cambridge: Harvard University Press.

Barra, A., Barra, A., Contucci, P., Sandell, R., and Vernia, C. (2014). An analysis of a large dataset on immigrant integration in Spain. The Statistical Mechanics perspective on Social Action. Scientific Reports 4: 4174.

Blau, P.M., Blum, T.C., and Schwartz, J.E. (1982). Heterogeneity and Intermarriage. American Sociological Review 47(1): 45-62. doi:10.2307/2095041.

Brock, W. and Durlauf, S.N. (2001). Discrete Choice with Social Interactions. The Review of Economic Studies 68(2): 235-260. doi:10.1111/1467-937X.00168.

Castles, S. and Miller, M.J. (2009). The Age of Migration - International Population Movements in the Modern World. New York: Pallgrave McMillian.

Cebolla, H. and González, A. (2008). La inmigración en España (2000-2007). De la gestión a la integración de los inmigrantes. Madrid: Centro de Estudios Políticos y Constitucionales.

Contucci, P. and Ghirlanda, S. (2007). Modeling society with statistical mechanics: an application to cultural contact and immigration. Quality \& Quantity 41(4): 569-578.

Contucci, P., Gallo, I., and Menconi, G. (2008). Phase transitions in social sciences: two-populations mean field theory. International Journal of Modern Physics B 22(14): 1-14. doi:10.1142/S0217979208039423.

Contucci, P. and Giardina, C. (2008). Mathematics and Social Sciences: A Statistical Mechanics Approach to Immigration. ERCIM News 782413: 8241.

Contucci, P., Sandell, R., and Seyedi, S. (2015). Forecasting the Integration of Immigrants. arXiv:1509.05447.

Cortina, C.T., Esteve, A., and Domingo, A. (2008). Marriage Patterns of the ForeignBorn Population in a New Country of Immigration: The Case of Spain. International Migration Review 42(4): 877-902. doi:10.1111/j.1747-7379.2008.00151.x.

European Commission (2010). EUROPE 2020: A strategy for smart, sustainable and inclusive growth. $\operatorname{COM}(2010)$.

Gallo, I., Barra, A., and Contucci, P. (2009). Parameter Evaluation of a Simple Mean- 
Field Model of Social Interaction. Mathematical Models and Methods in Applied Sciences. 19: 1427. doi:10.1142/S0218202509003863.

Hwang, S.S., Saenz, R., and Aguirre, B.E. (1997). Structural and Assimilationist Explanations of Asian American Intermarriage. Journal of Marriage and the Family 59(3): 758-72. doi:10.2307/353959.

Kalmijn, M. (1998). Intermarriage and Homogamy: Causes, Patterns, Trends. Annual Review of Sociology 24:395-421. doi:10.1146/annurev.soc.24.1.395.

Lanzieri, G. (2012). Mixed Marriages in Europe, 1990-2010. In: Doo-Sub, K. (ed.) Cross-Border Marriage: Global Trends and Diversity. Seoul: Korea Institute for Health and Social Affairs: 81-121.

McFadden, D. (2001) Economic choices. American Economic Review 91(3): 351-378. doi:10.1257/aer.91.3.351.

OECD (2014). International Migration Outlook 2014. Paris: OECD Publishing.

Portes, A. and Zhou, M. (1993). The New Second Generation: Segmented Assimilation and Its Variants. The Annals of the American Academy of Political and Social Science. 530:74-96. doi:10.1177/0002716293530001006.

Qian, Z., Glick, J.E., and Batson, C.D. (2012). Crossing Boundaries: Nativity, Ethnicity, and Mate Selection. Demography. 49(2): 651-75.

Van Tubergen, F. (2006). Immigrant Integration: A Cross-National Study. El Paso: LFB Scholarly Publishing LLC.

Weber, M. (1978) Economy and Society: An Outline of Interpretive Sociology. Berkeley: University of California Press. 